\title{
Telemonitoring, Telemedicine and Time in Range During the Pandemic: Paradigm Change for Diabetes Risk Management in the Post-COVID Future
}

\author{
Thomas Danne - Catarina Limbert - Manel Puig Domingo • \\ Stefano Del Prato $\cdot$ Eric Renard $\cdot$ Pratik Choudhary $\cdot$ Alexander Seibold (D
}

Received: May 27, 2021 / Accepted: July 1, 2021 / Published online: August 2, 2021

(C) The Author(s) 2021

\begin{abstract}
People with diabetes are at greater risk for negative outcomes from COVID-19. Though this risk is multifactorial, poor glycaemic control before and during admission to hospital for COVID-19 is likely to contribute to the increased risk. The COVID-19 pandemic and restrictions on mobility and interaction can also be expected to impact on daily glucose management of people with diabetes. Telemonitoring of glucose metrics has been widely used during the pandemic in people with diabetes,
\end{abstract}

\section{T. Danne $(\bowtie)$}

Diabetes Center for Children and Adolescents, Kinder- und Jugendkrankenhaus AUF DER BULT, Janusz-Korczak-Allee 12, 30173 Hannover, Germany e-mail: danne@hka.de

C. Limbert

Unit for Paediatric Endocrinology and Diabetes, CHULC, Hospital Dona Estefania, Lisbon, Portugal

C. Limbert

NOVA Medical School, Lisbon, Portugal

\section{Puig Domingo}

Endocrinology and Nutrition Service, Department of Medicine, Germans Trias i Pujol Research Institute and Hospital, Universitat Autònoma de Barcelona, Barcelona, Spain

S. Del Prato

Department of Clinical and Experimental Medicine, University of Pisa, Pisa, Italy including adults and children with T1D, allowing an exploration of the impact of COVID-19 inside and outside the hospital setting on glycaemic control. To date, 27 studies including 69,294 individuals with T1D have reported the effect of glycaemic control during the COVID19 pandemic. Despite restricted access to diabetes clinics, glycaemic control has not deteriorated for 25/27 cohorts and improved in 23/27 study groups. Significantly, time in range (TIR) $70-180 \mathrm{mg} / \mathrm{dL} \quad(3.9-10 \mathrm{mmol} / \mathrm{L}) \quad$ increased across $19 / 27$ cohorts with a median $3.3 \%$ ( $-6.0 \%$ to $11.2 \%$ ) change. Thirty per cent of

\section{E. Renard}

Department of Endocrinology, Diabetes, Nutrition, Montpellier University Hospital, Montpellier, France

\section{E. Renard}

Department of Physiology, Institute of Functional Genomics, CNRS, INSERM, University of Montpellier, Montpellier, France

P. Choudhary

Department of Diabetes and Nutritional Sciences, King's College London, London, UK

\section{P. Choudhary}

Diabetes Research Centre, University of Leicester, Leicester, UK

A. Seibold

Abbott Diabetes Care, Wiesbaden, Germany 
the cohorts with TIR data reported an average clinically significant TIR improvement of $5 \%$ or more, possibly as a consequence of more accurate glucose monitoring and improved connectivity through telemedicine. Periodic consultations using telemedicine enables care of people with diabetes while limiting the need for in-person attendance at diabetes clinics. Reports that sustained hyperglycaemia and early-stage diabetic ketoacidosis may go untreated because of the lockdown and concerns about potential exposure to the risk of infection argue for wider access to glucose telemonitoring. Therefore, in this paper we have critically reviewed reports concerning use of telemonitoring in the acute hospitalized setting as well as during daily diabetes management. Furthermore, we discuss the indications and implications of adopting telemonitoring and telemedicine in the present challenging time, as well as their potential for the future.

Keywords: Diabetes; Insulin pumps; Continuous glucose monitoring; Ambulatory glucose profile; Virtual care; COVID-19; Mortality; Risk management; Telemonitoring; Telemedicine

\section{Key Summary Points}

Despite restricted access to standard clinical care during the COVID-19 pandemic, glycaemic control has not deteriorated for people with type 1 diabetes using telemonitoring of glucose data.

The increased risk profile for severe COVID-19 disease on hospital admission for people with diabetes can be mitigated by application of telemonitoring and glucose-lowering treatment immediately following admission.

Routine telemonitoring can identify groups of at-risk individuals with diabetes who need in-person consultation and care, as well as those who may be successfully managed with telemedicine.
The COVID-19 pandemic has highlighted the unmet need for wider application of telemedicine and telemonitoring via CGM for people with diabetes, including those with hyperglycaemia and early-stage diabetic ketoacidosis that may go untreated during times of restricted clinical access.

The efficacy of diabetes digital health ecosystems has been validated during the COVID-19 public health emergency and argues for accelerated implementation of these models of care in diabetes.

\section{INTRODUCTION}

Following the outbreak and spreading of COVID-19, it became clear from analyses carried out in China, USA, Italy and UK that people with diabetes hospitalized for COVID-19 have higher risks of more severe outcomes, including increased risk of death [1-5]. A meta-analysis including 83 studies [6] confirmed that people with pre-existing diabetes admitted to hospital because of COVID-19 had a twofold higher risk of requiring intensive unit care $(n=22$ studies; odds ratio 2.10 ) and a nearly threefold higher risk of in-hospital death $(n=15$ studies; odds ratio 2.68). However, there are significant regional differences, with diabetes-related risks being more prominent in non-Asian versus Asian countries [6]. Outcomes have been claimed to differ between T1D and T2D with the risk of dying in hospital with COVID-19 being 3.5-fivefold higher in T1D and twofold in T2D compared to people without diabetes $[5,6]$. When adjusted for previous hospital admissions with coronary heart disease, cerebrovascular disease or heart failure, these increased risks for dying in hospital after contracting COVID-19 are 2.86 and 1.81 in $\mathrm{T} 1 \mathrm{D}$ and $\mathrm{T} 2 \mathrm{D}$, respectively. Mortality risk increases with age both in T1D and T2D and is emphasised in people over 70 years old, with the highest risks being for people over 80 years of age (relative risk 4.79 in T1D, 4.52 in T2D) [7]. However, it appears, that 
in T1D, only people over 50 years old, with longer duration of the disease $(80 \%$ with more than 15 years of disease) and raised $\mathrm{HbA1c}>$ $10 \%(86 \mathrm{mmol} / \mathrm{mol})$ are at higher risk of severe clinical outcomes of COVID-19 [4]. Amongst people with diabetes, those with prior hospital admission for diabetic ketoacidosis (DKA) or severe hypoglycaemia in the past 5 years were three times more likely to develop fatal or critical care unit-treated COVID-19 [8]. Notably, children and adolescents with diabetes do not appear to be at risk of more severe outcomes with COVID $[9,10]$. Prevalence, outcomes and prognosis in this group appear to be no different from their non-diabetic counterparts and consistently milder than adults with diabetes. A visual summary of the known risk factors is shown in Fig. 1.

The need to reduce the risk of community transmission of COVID-19 for vulnerable groups led to national guidance for people with diabetes to undertake extreme social distancing and shielding in place that minimises infection risk, including attendance at diabetes clinics. Extreme social distancing during the global COVID-19 pandemic meant that people with diabetes have reduced or had no access to their regular face-to-face diabetes services, being replaced in most cases with a reduced frequency of telephone or video consultations. For people with diabetes who can uplink glucose data to the cloud and connect remotely with their healthcare provider, such as users of continuous

Box 1. Definitions for Telemedicine and Telemonitoring in Context of Diabetes Care

Telemedicine Managing diabetes care using telecommunications technology, including telephone and video conferencing, to deliver care at a distance. In this way, a healthcare professional (HCP) in one location can provide a medical consultation, including treatment adjustment, to a patient at a distant site. Telemedicine can also involve multiple HCPs in a synchronous patient consultation or care review.

Telemonitoring The use of diabetes-specific medical devices that can monitor, transmit and share indicators of diabetes health between a person with diabetes and their diabetes care team. Telemonitoring allows care of patients at home or at other locations remote from their HCPs, using mobile phones, tablet computers, and desktop computers. Telemonitoring allows information, such as interstitial glucose readings from CGM systems, to be stored and reviewed by separate members of the diabetes care team, including the patient.

\begin{tabular}{|c|c|c|c|c|}
\hline Risk & Infection $^{36}$ & Hospitalization $^{4,37}$ & Critical Care $^{8}$ & Death $^{2,4,8,37}$ \\
\hline High & - Adults, $\mathrm{HbA1} \geq \geq 9.0 \%$ & - Adults, HbA1c $\geq 8.0 \%$ & $\begin{array}{l}\text { - New-onset diabetes } \\
\text { - Prior hospitalization for DKA } \\
\text { or severe hypoglycemia }\end{array}$ & $\begin{array}{l}\text { - New-onset diabetes } \\
\text { - Prior hospitalization for DKA or } \\
\text { severe hypoglycemia } \\
\text { - Adults T1D >80 years } \\
\text { - Adults T2D >80 years } \\
\text { - Adults HbA1c } \geq 10.0 \% \\
\text { - eGFR }<44\end{array}$ \\
\hline Medium & - Adults, HbA1c 8.0- $9.0 \%$ & Adults, HbA1c 7.0- 8.0\% & & $\begin{array}{l}\text { - Adults T1D }>70 \text { yrs old } \\
\text { - Adults T2D }>70 \text { yrs old } \\
\text { - Adults HbA1c } 9.0-10.0 \% \\
\text { - eGFR }<45-59\end{array}$ \\
\hline Low & $\begin{array}{l}\text { - Adults, HbA1c }<7.0 \% \\
\text { - Children \& Adolescents, } \\
\text { any HbA1c }\end{array}$ & $\begin{array}{l}\text { - Children \& Adolescents, } \\
\text { any HbA1c }\end{array}$ & $\begin{array}{l}\text { - Children \& Adolescents, any } \\
\text { HbA1c }\end{array}$ & $\begin{array}{l}\text { - Children \& Adolescents, any } \\
\text { HbA1c }\end{array}$ \\
\hline
\end{tabular}

Fig. 1 Risk matrix for people during the COVID-19 pandemic. Summary of the known risk factors for infection and disease severity with COVID 19. eGFR estimated glomerular filtration rate $\left(\mathrm{ml} / \mathrm{min} / 1.73 \mathrm{~m}^{2}\right)$, T1D type 1 diabetes, T2D type 2 diabetes 
Table 1 Studies reporting glycaemic metrics before and during COVID-19 social lockdown

\begin{tabular}{|c|c|c|c|c|c|}
\hline Study & Region & $\begin{array}{l}\text { Adults/ } \\
\text { children }(n)\end{array}$ & Type & System & $\begin{array}{l}\text { Change in glycaemic } \\
\text { metrics }\end{array}$ \\
\hline Bonora BM [17] & Italy & Adults (33) & T1D & FreeStyle Libre & $\begin{array}{l}\text { AG, mg/dL 177-160 } \\
\quad(p=0.005) \\
\text { \%TIR 54-65.2 }(p=0.01) \\
\text { \%TAR1 42.3-31.6 } \\
\quad(p=0.016) \\
\text { SD, mg/dL 58.9-53.2 } \\
\quad(p<0.05)\end{array}$ \\
\hline Capaldo B [19] & Italy & Adults (207) & T1D & $\begin{array}{l}\text { FreeStyle Libre }(n=130) \\
\text { Medtronic Guardian }(n=47) \\
\text { Dexcom G6 }(n=18) \\
\text { Eversense }(n=12)\end{array}$ & $\begin{array}{l}\text { \% TIR 55.6-58.2 } \\
\quad(p=0.002) \\
\text { \%TBR2 1.42-0.58 } \\
\quad(p<0.001) \\
\text { \%CV 35.9-34.7 } \\
(p=0.001)\end{array}$ \\
\hline Schiaffini R [21] & Italy & Children (22) & T1D & Dexcom G6 & $\begin{array}{l}\text { \%TIR 61.45-66.41 } \\
\quad(p<0.001) \\
\text { \%TAR1 34.73-29.86 } \\
\quad(p<0.001) \\
\text { TDD, IU/day } 7.9-5.3 \\
(p<0.001)\end{array}$ \\
\hline $\begin{array}{l}\text { Christoforidis A } \\
\text { [77] }\end{array}$ & Greece & Children (34) & T1D & Medtronic Enlite & $\begin{array}{c}\text { \%CV 39.5-37.4 } \\
(p=0.011)\end{array}$ \\
\hline Fernández E [78] & Spain & Adults (307) & T1D & FreeStyle Libre & $\begin{array}{l}\text { AG, mg/dL 167-158 } \\
\quad(p<0.001) \\
\text { \%TIR 57.8-62.5 } \\
\quad(p<0.001) \\
\text { \% TBR1 4.9-5.5 } \\
\quad(p<0.001) \\
\text { \% TAR1 37.3-32.0 } \\
\quad(p<0.001) \\
\text { eA1c } 7.4-7.1(p<0.001)\end{array}$ \\
\hline Mesa A [15] & Spain & Adults (92) & T1D & $\begin{array}{l}\text { Free Style Libre }(n=75) \\
\text { Dexcom G5 }(n=17)\end{array}$ & $\begin{array}{l}\text { \%TIR 59.3-62.6 }(p<0.05) \\
\text { \%TAR1 34.4-30.7 } \\
(p<0.05) \\
\text { GMI, \% 7.2-7.0 }(p<0.05)\end{array}$ \\
\hline
\end{tabular}


Table 1 continued

\begin{tabular}{|c|c|c|c|c|c|}
\hline Study & Region & $\begin{array}{l}\text { Adults/ } \\
\text { children }(n)\end{array}$ & Type & System & $\begin{array}{l}\text { Change in glycaemic } \\
\text { metrics }\end{array}$ \\
\hline $\begin{array}{l}\text { Cotovad-Bellas L } \\
\text { [79] }\end{array}$ & Spain & Adults (44) & T1D & FreeStyle Libre & $\begin{array}{l}\text { No change during } \\
\text { lockdown }\end{array}$ \\
\hline Caruso I [80] & Italy & Adults (48) & T1D & FreeStyle Libre & $\begin{array}{c}\text { \% TBR1 6.3-4.5 } \\
\quad(p<0.001) \\
\text { \%CV 38.3-35.1 } \\
\quad(p=0.008)\end{array}$ \\
\hline Aragona M [81] & Italy & Adults (63) & T1D & $\begin{array}{l}\text { FreeStyle Libre }(n=52) \\
\text { Dexcom G6 }(n=11)\end{array}$ & $\begin{array}{l}\text { AG, mg/dL 165-158 } \\
\quad(p=0.04) \\
\text { \%TIR 58-61 }(p<0.05) \\
\text { \%TAR1 38-34 }(p<0.04) \\
\text { GMI, \% 7.2-7.0 } \\
\quad(p=0.016)\end{array}$ \\
\hline Dover AR [22] & UK & Adults (572) & T1D & FreeStyle Libre & $\begin{array}{l}\text { AG, mmol/L 9.6-9.3 } \\
\quad(p<0.001) \\
\text { \%TIR 53-56 }(p<0.001) \\
\text { \%TBR 3-3 }(p=0.005) \\
\text { \%TAR1 42-39 }(p<0.001) \\
\text { eA1c 61-58 }(p<0.001)\end{array}$ \\
\hline Di Dalmazi G [82] & Italy & $\begin{array}{l}\text { Children } \\
\leq 12 \text { years } \\
(30)\end{array}$ & T1D & $\begin{array}{l}\text { Freestyle Libre }(n=2) \\
\text { Dexcom G5 or G6 }(n=28)\end{array}$ & SD 67.4-64.3 $(p=0.029)$ \\
\hline Di Dalmazi G [82] & Italy & $\begin{array}{l}\text { Teenagers } \\
13-17 \text { years } \\
(24)\end{array}$ & T1D & $\begin{array}{l}\text { Freestyle Libre }(n=2) \\
\text { Dexcom G5 or G6 }(n=22)\end{array}$ & $\begin{array}{l}\text { No change during } \\
\text { lockdown }\end{array}$ \\
\hline
\end{tabular}


Table 1 continued

\begin{tabular}{|c|c|c|c|c|c|}
\hline Study & Region & $\begin{array}{l}\text { Adults/ } \\
\text { children }(n)\end{array}$ & Type & System & $\begin{array}{l}\text { Change in glycaemic } \\
\text { metrics }\end{array}$ \\
\hline Di Dalmazi G [82] & Italy & Adults (76) & T1D & $\begin{array}{l}\text { Freestyle Libre }(n=41) \\
\text { Dexcom G5/G6 }(n=35)\end{array}$ & $\begin{array}{l}\text { AG, mg/dL 164-160 } \\
\quad(p=0.001) \\
\text { \%TIR 57.7-61.3 } \\
(p<0.001) \\
\text { \% TBR1 2.5-3.0 } \\
(p=0.019) \\
\text { \%TAR1 26.5-25.1 } \\
(p=0.001) \\
\text { \%TAR2 11.1-7.8 } \\
(p=0.007) \\
\text { SD 63.0-59.6 }(p=0.016) \\
\text { eAlc, \% 7.2-6.8 } \\
(p<0.001) \\
\text { GMI,\% 7.7-7.6 }(p=0.001)\end{array}$ \\
\hline Brener A [83] & Israel & Children (102) & T1D & Dexcom G5 & $\begin{array}{l}\text { No change during } \\
\text { lockdown }\end{array}$ \\
\hline Pla B [84] & Spain & Adults (50) & T1D & FreeStyle Libre & $\begin{array}{l}\text { AG, mg/dL } 160.3-150.0 \\
\quad(p<0.001) \\
\% \text { TIR 57.5-65.8 } \\
\quad(p<0.001) \\
\% \mathrm{CV} 40.7-36.4 \\
(p<0.001) \\
\text { eAlc, \% 7.2-6.8 } \\
(p<0.001) \\
\text { GMI,\% 7.2-6.9 }(p<0.001)\end{array}$ \\
\hline $\begin{array}{l}\text { Prabhu Navis J } \\
\text { [18] }\end{array}$ & UK & Adults (269) & T1D & $\begin{array}{l}\text { Freestyle Libre }(n=190) \\
\text { Dexcom G6 }(n=79)\end{array}$ & $\begin{array}{l}\text { \% TIR 57.5-59.6 } \\
\quad(p=0.002) \\
\text { \%CV 37-36 }(p=0.003)\end{array}$ \\
\hline Barchetta I [14] & Italy & Adults (50) & T1D & $\begin{array}{l}\text { FreeStyle Libre and other CGM, } \\
\text { unspecified }\end{array}$ & $\begin{array}{l}\text { AG, mg/dL 154-165 } \\
\quad(p=0.027) \\
\text { \%TIR 75-69 }(p<0.001) \\
\text { \%TBR1 6-10 }(p=0.002) \\
\text { eAlc 7.3-7.5 }(p=0.031)\end{array}$ \\
\hline
\end{tabular}


Table 1 continued

\begin{tabular}{|c|c|c|c|c|c|}
\hline Study & Region & $\begin{array}{l}\text { Adults/ } \\
\text { children }(n)\end{array}$ & Type & System & $\begin{array}{l}\text { Change in glycaemic } \\
\text { metrics }\end{array}$ \\
\hline Predieri B [85] & Italy & Children (62) & T1D & Dexcom G6 & $\begin{array}{l}\text { \% TIR 60.0-62.1 } \\
\quad(p=0.008) \\
\text { \%TAR1 37.8-35.7 } \\
(p=0.048) \\
\text { \%TBR1 2.63-2.13 } \\
(p=0.001) \\
\text { \%TBR2 } 0.5-0.34 \\
(p=0.002)\end{array}$ \\
\hline Braune K [23] & Germany & Children (28) & T1D & $\begin{array}{l}\text { Freestyle Libre }(n=9) \\
\text { Dexcom G5/G6 }(n=6) \\
\text { Medtronic Guardian }(n=13)\end{array}$ & $\begin{array}{l}\text { \%TIR 46.9-56.3 } \\
\quad(p=0.016) \\
\text { \%TAR1 21.3-13.9 } \\
\quad(p=0.013)\end{array}$ \\
\hline Potier L [20] & France & Adults (1378) & T1D & FreeStyle Libre & $\begin{array}{l}\mathrm{AG}, \mathrm{mmol} / \mathrm{L} 9.1-8.7 \\
\quad(p<0.001)\end{array}$ \\
\hline Boscari F [24] & Italy & Adults (79) & T1D & $\begin{array}{l}\text { FreeStyle Libre }(n=52) \\
\text { Dexcom }(n=16) \\
\text { Other CGM }(n=3)\end{array}$ & $\begin{array}{l}\text { AG, mg/dL 161.1-156.3 } \\
\quad(p=0.001) \\
\text { \%TIR 63.6-66.3 } \\
\quad(p<0.001) \\
\text { \%TAR1 33.4-30.5 } \\
(p=0.002)\end{array}$ \\
\hline $\begin{array}{l}\text { Sánchez Conejero } \\
\text { M [86] }\end{array}$ & Spain & Children (80) & T1D & $\begin{array}{l}\text { FreeStyle Libre }(n=15) \\
\text { Medtronic Guardian }(n=52) \\
\text { Dexcom G6 }(n=13)\end{array}$ & $\begin{array}{l}\text { \%TIR 72.1-74.8 }(p=0.01) \\
\text { \%TAR2 4.6-3.7 } \\
(p=0.038) \\
\text { \%TBR1 4.6-3.2 } \\
(p<0.001) \\
\text { \%TBR2 1.2-0.7 } \\
(p<0.001) \\
\text { \%CV 35.8-33.1 } \\
(p<0.001)\end{array}$ \\
\hline
\end{tabular}


Table 1 continued

\begin{tabular}{|c|c|c|c|c|c|}
\hline Study & Region & $\begin{array}{l}\text { Adults/ } \\
\text { children }(n)\end{array}$ & Type & System & $\begin{array}{l}\text { Change in glycaemic } \\
\text { metrics }\end{array}$ \\
\hline Rachmiel M [25] & Israel & Children (195) & T1D & Unspecified CGM & $\begin{array}{l}\text { AG, mg/dL 164-160 } \\
\quad(p<0.001) \\
\text { \%TIR 59-63 }(p<0.001) \\
\text { \%TAR1 32.0-38.6 } \\
\quad(p=0.005) \\
\text { \%CV 37.1-35.6 } \\
(p=0.002) \\
\text { eA1c, \% 7.35-7.20 } \\
(p<0.001)\end{array}$ \\
\hline Marigliano M [87] & Italy & Children (233) & T1D & $\begin{array}{l}\text { FreeStyle Libre }(n=98) \\
\text { Dexcom G6 }(n=100) \\
\text { SMBG }(n=35)\end{array}$ & $\begin{array}{l}\text { AG, mg/dL 178.6-169.1 } \\
\quad(p<0.001) \\
\text { \%TIR 52.6-58.0 } \\
\quad(p<0.001) \\
\text { \%TAR1 43.4-38.0 } \\
\quad(p<0.001) \\
\text { SD 68.0-63.6 }(p<0.001) \\
\text { GMI, \% 7.60-7.37 } \\
\quad(p<0.001)\end{array}$ \\
\hline Alharthi SK [26] & $\begin{array}{l}\text { Saudi } \\
\text { Arabia }\end{array}$ & Adults (101) & T1D & Unspecified CGM & $\begin{array}{l}\text { AG, mg/dL 180-159 } \\
\quad(p<0.001) \\
\text { \%TIR 46-55 }(p<0.001) \\
\text { \%TAR1 48-35 }(p<0.001) \\
\text { GMI,\% 7.7-7.2 }(p=0.03)\end{array}$ \\
\hline $\begin{array}{l}\text { van der Linden J } \\
\text { [88] }\end{array}$ & USA & NA $(65,067)$ & All & Dexcom G6 & \%TIR 59-61 $(p<0.001)$ \\
\hline
\end{tabular}


Table 1 continued

\begin{tabular}{|c|c|c|c|c|c|}
\hline Study & Region & $\begin{array}{l}\text { Adults/ } \\
\text { children }(n)\end{array}$ & Type & System & $\begin{array}{l}\text { Change in glycaemic } \\
\text { metrics }\end{array}$ \\
\hline \multirow[t]{3}{*}{ Viñals C [16] } & Spain & Adults (59) & T1D & Medtronic 640G + Enlite & $\begin{array}{l}\text { AG, mg/dL } 153.2-147.8 \\
\quad(p<0.001)\end{array}$ \\
\hline & & & & & $\begin{array}{l}\text { \%TIR 67.6-69.8 } \\
(p<0.017)\end{array}$ \\
\hline & & & & & $\begin{array}{l}\text { eAlc, \% 6.94-6.75 } \\
(p<0.001)\end{array}$ \\
\hline
\end{tabular}

Studies are listed in date order as disclosed on PubMed. Significant changes in glycaemic metrics from before to during COVID-19 lockdown are presented. Each number sequence indicates change from before to during lockdown with $p$ value $A G$ average glucose, $e A 1 c$ estimated $\mathrm{HbAlc} \% C V \%$ coefficient of mean glucose, GMI glucose management indicator, \%TIR percentage time in range $70-180 \mathrm{mg} / \mathrm{dL}(3.9-10 \mathrm{mmol} / \mathrm{L}), \% T B R 1$ percentage time below range $<70 \mathrm{mg} / \mathrm{dL}(3.9 \mathrm{mmol} /$ $\mathrm{L})$, \%TBR2 percentage time below range $<54 \mathrm{mg} / \mathrm{dL}(3.0 \mathrm{mmol} / \mathrm{L}), \% T A R 1$ percentage time above range $>180 \mathrm{mg} / \mathrm{dL}$ $(10 \mathrm{mmol} / \mathrm{L}), \% T A R 1$ percentage time above range $>250 \mathrm{mg} / \mathrm{dL}(13.8 \mathrm{mmol} / \mathrm{L}), T D D$ total daily dose of bolus insulin, $N A$ no information about demogaphics

glucose monitoring (CGM), including flash glucose monitoring, clinical review of glucose control and shared decision-making in regard to treatment adjustment has been accomplished via telemedicine and glucose telemonitoring tools. Substantial evidence now indicates that this has been effective (Table 1). Routine care was then effectively switched to telemedicine and digital services, including for diabetes reviews and self-management support, and published data has demonstrated that glucose control was not impaired while access to regular diabetes clinical services was interrupted [11]. This review summarises available data on the importance both of telemonitoring and telemedicine, as defined in Box 1, in effective diabetes management for reducing the risks for COVID-19 infection. This article is based on previously conducted studies and does not contain any new studies with human participants or animals performed by any of the authors.

\section{STUDIES REPORTING GLUCOSE METRICS BEFORE AND DURING COVID-19 SOCIAL LOCKDOWN}

Studies were reviewed that reported data on remote monitoring with CGM technologies that has enabled clinicians and people with diabetes to view and discuss glucose downloads together during this period. In the absence of routine laboratory HbA1c testing, several studies, since the start of the COVID-19 pandemic, have used percentage time in range (\%TIR) and other CGM-derived metrics [12] to determine the degree of glycaemic control. \%TIR is indeed becoming established as a significant indicator of immediate and medium-term glucose control [13]. Table 1 summarises the various studies published between March 2020 and March 2021. Each of the studies selected individual before and during lockdown criteria for comparison of glucose metrics, typically benchmarking lockdown as starting in the middle to end of March 2020.

\section{TIME IN RANGE DURING COVID-19}

Across the 27 cohorts studied, \%TIR increased significantly in 19 of them, and did not change in 7 of them. Significantly, time in range (TIR) 70-180 mg/dL/3.9-10 mmol/L improved across $18 / 27$ cohorts with a median change (range) of $3.3 \%$ ( -6.0 to $11.2 \%$ ), covering 67,587 individuals using CGM sensors. Notably, $30 \%$ of the cohorts with TIR data reported clinically significant TIR improvements of 5\% or more [13]. Only 
in the study by Barchetta et al. [14] did \%TIR deteriorate during the lockdown period. In this study, lockdown-associated stress due to loss of work or furlough from work independently predicted impaired TIR after adjustment for potential confounders. Subjects in this study also experienced an increase in percentage time above range (\%TAR) and percentage time below range (\%TBR) during the lockdown. This aligns with observations from Bonora et al. [17], who have reported that improvements in \%TIR and \%TAR were restricted to those who stayed at home during lockdown, whereas those still experiencing the stress of on-site working saw no change. Reductions in TAR and in average glucose are present in 13/27 cohorts and 13/27 cohorts, respectively, indicative of the increases in \%TIR. \%TBR $<70 \mathrm{mg} / \mathrm{dL} \quad(<3.9 \mathrm{mmol} / \mathrm{L})$ decreased only in $4 / 27$ cohorts and increased in $3 / 27$ cohorts, with no change in the rest, including in subjects prone to hypoglycaemia $[16,17]$. When reported, improvements in \%TIR in T1D after lockdown are negatively associated with baseline \%TIR [18], with greater improvements seen for people with lower \%TIR prelockdown. Baseline HbA1c is also predictive of greater improvement in \%TIR, such that people in whom \%TIR improved by $5 \%$ or more were more likely to have a higher pre-lockdown HbA1c [18].

It has been suggested that restrictions on community, social and leisure time provided more time for diabetes self-management during the lockdown periods and may have contributed to improved glycaemic control in this period. Again, in favour of this idea are the outcomes from the cohort in Italy, showing that CGM users who stayed at home during lockdown had significant improvements in average glucose and \%TIR, whereas those who continued working did not. Capaldo and colleagues [19] indicated that improvements in \%TIR and reduced glycaemic variability amongst their cohort are associated with reduced physical activity, more regular meal patterns and a change in sleeping patterns. Equally, the reduction in average glucose reported by Potier [20] was associated with positive behavioural changes. The importance and efficacy of greater parental care of children with T1D while access to standard paediatric care is interrupted has been shown by another Italian study on 22 children [21] that showed a significant increase in \%TIR and reduction in \%TAR during COVID-enforced home care for this group. Notably, this improvement seems to be associated with greater use of correction boluses. The downside of these otherwise encouraging assessments was highlighted in the study by Dover and colleagues [22]. Although CGM metrics improved across the study group $(n=572)$, they also demonstrated a deterioration of at least $5 \%$ TIR in a subset of patients $(n=125)$ and that this was significantly associated with higher levels of socio-economic deprivation. This must be included in learnings from the enforced shielding during COVID-19 in order to ensure that a care gap does not emerge in the application of diabetes technology once the COVID-19 pandemic is over.

Most of the studies included did not include a formal telemedicine component, rather they collected data from an observational standpoint and made no assessment of the nature of telemedicine contacts between patients and their diabetes HCPs, although these are acknowledged to have happened. However, 4/27 studies did involve an active telemedicine intervention and in each of these studies [23-26] there was an improvement in glucose metrics. Most tellingly, in the study by Alharthi [26], CGM users were categorized into two groups, one that participated in a single telemedicine consult during the 6-week lockdown study period $(n=61)$ and one that did not $(n=40)$. Those who attended a telemedicine visit had a significant improvement in average glucose, GMI, \%TIR and \%TAR. In contrast, there were no significant changes in any CGM metrics in the group that did not receive a telemedicine consultation.

\section{DIABETES CONTROL IN ABSENCE OF TELEMONITORING}

The question must be asked as to the glucose control of people with diabetes who have not had access to telemonitoring with CGM. Overall, the expected deterioration in glycaemic control is only variably evident. Two studies 
have indicated that people with T2D have seen their HbA1c rise during COVID $[27,28]$ but in at least one of these studies the rise has been for people with diabetes less than 50 years of age [27] but not older. Balancing these observations are studies showing that COVID-19 home confinement did not negatively impact glucose control in patients with T2D [29], although older age and insulin therapy are associated with greater risk of deterioration of glucose control, and a separate study has observed a fall in HbA1c during the COVID restrictions [30]. A study from the Netherlands found that, during the COVID-19 lockdown, people with relatively well-controlled T1D or T2D showed increased stress and weight gain but no deterioration in glucose control [31]. A section of the study group was CGM users so it is hard to interpret these findings. In T1D, an increase both in average glucose and HbA1c was reported in a small cohort of people in India [32]; however, this appears to be mainly due to non-availability of insulin or self-monitoring blood glucose (SMBG) strips during the lockdown period.

\section{COSTS OF COVID IN DIABETES POINT TO NEED FOR EFFECTIVE TELEMEDICINE}

For healthcare services, a move towards telemonitoring for care of people with chronic conditions, including diabetes, has been part of a long-term plan [33]. However, the COVID-19 public health emergency has forced the acceleration of this process. The increased risks of severe disease and death for people with diabetes contracting COVID are evident but these are also matched by a significant financial impact. An analysis of hospital admissions across Europe [34] during the period January-June 2020 has calculated that the total costs for treating people with diabetes admitted to hospital with COVID-19 during this period was $€ 3.38$ billion, which is approximately $24 \%$ of all COVID-related admission costs. Of particular note is that varying costs are associated with the type of diabetes and the level of metabolic control [34]. Thus, each admission for a person with T1D who has HbA1c close to target $<7.5 \%(58 \mathrm{mmol} / \mathrm{mol})$ is associated with a cost of $€ 28,997$, whereas a person with T1D and higher HbA1c $(\geq 7.5 \%$; $58 \mathrm{mmol} / \mathrm{mol})$ would cost $€ 57,244$. For people with T2D these costs are $€ 25,018$ and $€ 46,130$. The lesson is that maintaining good glucose control is of high value, even if telemonitoring and telemedicine have not prevented a COVID-related hospitalization.

\section{HYPERGLYCAEMIA IS A SIGNIFICANT RISK FACTOR FOR COVID INFECTION, HOSPITALIZATION AND DEATH}

That diabetes is a significant risk factor for COVID infection and subsequent severe disease is accepted [4,6,35]. A significant part of this risk profile can be attributed to hyperglycaemia. Amongst a cohort of 183 people with diabetes in Israel, HbA1c was shown to predict contracting COVID-19 and subsequent hospitalization [33] (Fig. 2). Amongst this cohort, those with an $\mathrm{HbA1c}$ of $8.0-8.9 \%(64-74 \mathrm{mmol} / \mathrm{mol})$ had a 1.56 increased odds ratio contracting COVID compared to people with HbA1c $<7.0 \%$ $(<53 \mathrm{mmol} / \mathrm{mol})$, and those with HbA1c $\geq 9.0 \%$ ( $\geq 75 \mathrm{mmol} / \mathrm{mol})$ had an odds ratio of 1.84. Regarding hospitalization following infection, compared to an HbA1c $<7.0 \%$ $(<53 \mathrm{mmol} / \mathrm{mol})$, levels of $7.0-7.9 \% \quad$ (53$63 \mathrm{mmol} / \mathrm{mol}), \quad 8.0-8.9 \% \quad(64-74 \mathrm{mmol} / \mathrm{mol})$ or $\geq 9.0 \%$ ( $\geq 75 \mathrm{mmol} / \mathrm{mol}$ ) increased the odds of hospitalization by $2.4,3.2$ and 3.4 , respectively [36].

Regarding mortality from COVID in hospital, the OpenSAFELY analysis of over 17 million primary care records [37] indicates that, when adjusted for all covariables, adults with diabetes and $\mathrm{HbA} 1 \mathrm{c}$ of $<7.5 \%(<58 \mathrm{mmol} / \mathrm{mol})$ have a 1.31 hazard ratio for death with COVID, which rises to 1.95 for $\mathrm{HbA} 1 \mathrm{c} \geq 7.5 \%$ ( $\geq 58 \mathrm{mmol} / \mathrm{mol}$ ). More specifically, Holman and colleagues [4] showed that people with T1D and $\mathrm{HbA} 1 \mathrm{c} \geq 10 \%(86 \mathrm{mmol} / \mathrm{mol})$ had a 2.23 fold increased risk of death compared to those with an HbA1c of $6.5-7.0 \%(48-53 \mathrm{mmol} / \mathrm{mol})$. People with T2D had a 1.22-fold risk of death 

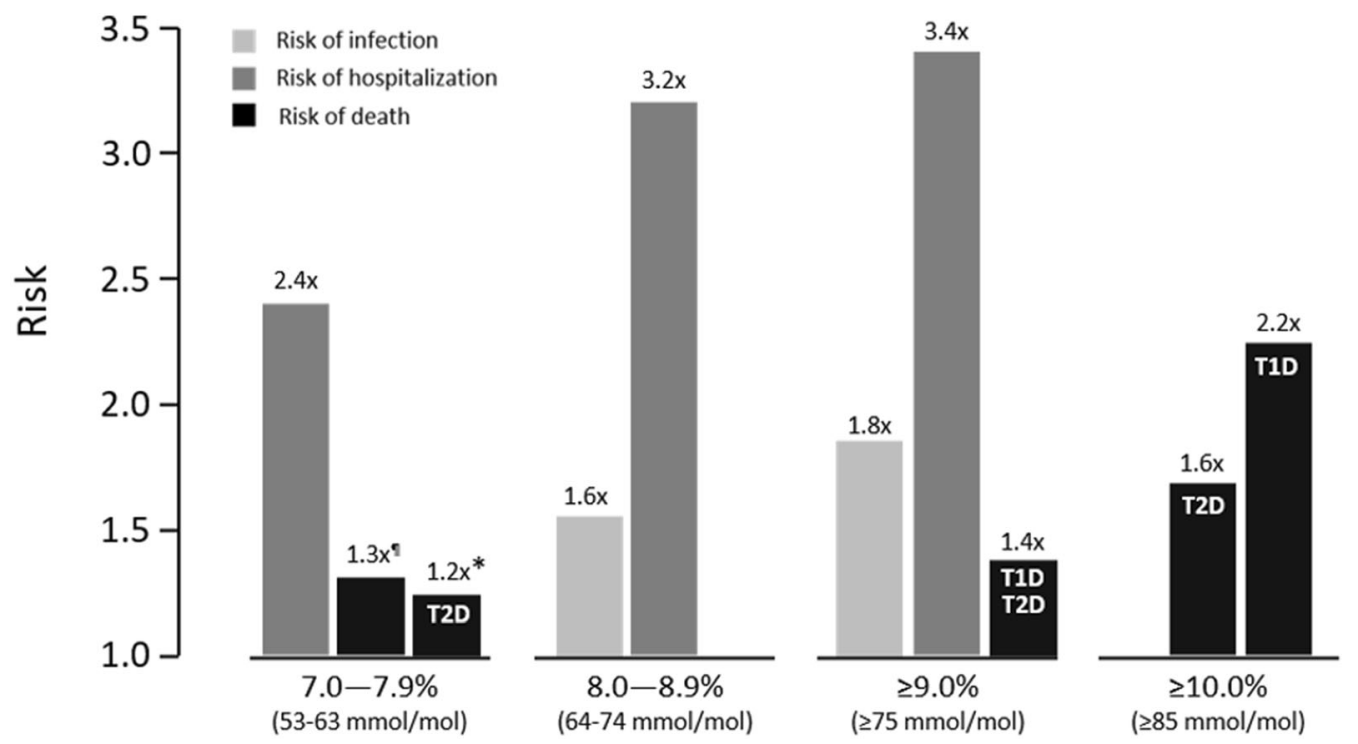

Fig. 2 Hyperglycaemic risk profiles for COVID-related disease and mortality. "For HbAlc $<7.5 \%$ $(58 \mathrm{mmol} / \mathrm{mol}) \quad[37]$ *For $\quad$ HbAlc $\geq 7.6 \%$ $(60 \mathrm{mmol} / \mathrm{mol})$ [4]. Risk profiles compared to HbAlc < $7.0 \%(53 \mathrm{mmol} / \mathrm{mol})$. Data derived from relative risk [4],

with $\quad$ HbA1c levels $\geq 7.6 \% \quad(59 \mathrm{mmol} / \mathrm{mol})$ compared to those with HbA1c of $6.5-7.0 \%$ (48-53 $\mathrm{mmol} / \mathrm{mol})$, rising to 1.36 above $9.0 \%$ $(75 \mathrm{mmol} / \mathrm{mol})$ and 1.61 above $10 \%$ $(85 \mathrm{mmol} / \mathrm{mol})$. These significant associations reinforce the evidence that hyperglycaemia at admission increases in-patient mortality with COVID-19, both for people with pre-existing diabetes or without [38-40]. The importance of hyperglycaemia in COVID infection is linked to a number of hypotheses [41-43] whereby SARSCoV-2 infection is facilitated then potentiated by the generalized multisystemic inflammation process observed that further drives the hyperglycaemic state.

\section{Importance of Telemonitoring Following COVID-Related Admission and Hyperglycaemia}

Glucose telemonitoring is emphasised for patients admitted to hospital with COVID, both those with diabetes and those without diabetes but high admission glucose. Using CGM in 35 patients with COVID and diabetes, Shen et al.

[44] showed that \%TAR $>160 \mathrm{mg} / \mathrm{dL}$ $(>8.9 \mathrm{mmol} / \mathrm{L}) \quad$ or $\quad \% \mathrm{TBR}<70 \mathrm{mg} / \mathrm{dL}$ $(<3.9 \mathrm{mmol} / \mathrm{L})$ is associated with up to $2.45-$ fold increased odds ratio of ICU admission, mechanical ventilation or hypotension/multiple organ dysfunction. Length of hospital stay was also associated with \%TAR and \%TBR. Significantly, the odds ratio for adverse outcomes was also increased with glycaemic variability (GV) above a coefficient of variation (CV) of $36 \%$. The implication is that maintaining TIR $70-160 \mathrm{mg} / \mathrm{dL}(3.9-8.9 \mathrm{mmol} / \mathrm{L})$ as close to $70 \%$ as possible is a management strategy that should be targeted for all patients admitted to hospital with hyperglycaemia and COVID.

The need to maintain good glucose control is supported by the analysis of Klonoff and colleagues [45], who noted that severe hyperglycaemia $\quad(>250 \mathrm{mg} / \mathrm{dL} />13.9 \mathrm{mmol} / \mathrm{L})$ on days 2-3 after admission was independently associated with high mortality (adjusted hazard ratio 7.17 ; 95\% CI 2.62-19.62) compared with patients with glucose $<140 \mathrm{mg} / \mathrm{dL}(<7.8 \mathrm{mmol} /$ L). Notably, reducing high admission glucose to $141-180 \mathrm{mg} / \mathrm{dL}(7.8-10 \mathrm{mmol} / \mathrm{L})$ by day $2-3$ was shown to significantly reduce the risk of 
mortality [45]. The impact of concurrent COVID with DKA and hyperglycaemic hyperosmolar syndrome (HSS) on post-admission outcomes [46] also argues for the application of immediate telemonitoring and glucose-lowering treatment following admission. Given that regular glucose monitoring using standard point-of-care testing exposes hospital teams to risk of COVID infection, the importance of telemonitoring that aids anti-glycaemic therapy whilst reducing frequent patient contact is strongly indicated.

\section{Risk of New-Onset Diabetes Because of COVID-19 Infection}

Evidence that infection with COVID-19 may precipitate diabetes is also emerging [42]. The SARS-CoV virus, which caused the SARS epidemic, is reported to bind angiotensin-converting enzyme 2 (ACE2) receptors in the pancreas with consequent damage to islet cells and reduced insulin release [40,47]. Compared to healthy siblings, SARS infection resulted in symptomatic T2D during hospitalization in half of cases, with $5 \%$ remaining diabetic 3 years later. During the COVID-19 pandemic, SARSCoV-2 infection has been associated with the subsequent onset of insulin-dependent diabetes [48], presenting with DKA in a young man with severe loss of $\beta$-cell function but no islet-specific autoantibodies. Direct SARS-CoV-2-mediated $\beta$ cell damage is proposed as the cause of the T1D manifested in this case [48]. Similar associations have been made for children [49].

\section{NEWLY DIAGNOSED DIABETES AND NEED FOR EARLY GLUCOSE CONTROL}

In addition, several strands of evidence indicate that newly diagnosed diabetes should be a clear target for immediate glucose control. In the context of COVID-19, people with newly diagnosed diabetes are at most risk of COVID-related admission to intensive care or death [50], with three times the risk of people with preexisting diabetes $[2,50]$ and an increased length of stay in hospital. This increased mortality has been linked to more severe organ damage amongst people with newly diagnosed diabetes [51], suggestive of a metabolic disruption that is mitigated following diabetes therapy.

In these studies, the designation of 'newly diagnosed' refers to their hyperglycaemia state detected in hospital rather than a 'recent diagnosis'. However, the increased risk is not solely due to hyperglycaemia, since their glucose levels are typically lower than people with preexisting diabetes or without diabetes at the point of admission [2]. Of course it is difficult to ascertain if a proportion of these patients may have had undiagnosed diabetes at the point of infection. Therefore it is important to better understand the metabolic fragility of a person with diabetes at the point of diagnosis and immediately thereafter, and also to take steps to overcome this state. Further research is required to establish the extent and duration of 'new onset' risk following diagnosis and the pathophysiology associated with it. This would be an important role for telemonitoring with CGM systems, which can both help educate the new patient and also help improve their glycaemic dysregulation.

\section{Managing New-Onset Type 1 Diabetes Using Telemedicine}

Insulin initiation in new-onset T1D is another important aspect of telemedicine for people with diabetes that has typically emphasised inperson clinic attendance and face-to-face training. This standard approach has been another casualty of the COVID-19 pandemic, despite the evidence that this group are at high risk of COVID-related harm. In two case reports, telemedicine has been used effectively and safely as part of the insulin initiation, including dose titration, as well as to provide education on diabetes management and support. These reports describe a newly diagnosed adult and a 12-month-old child [52]. Both cases did involve initial emergency hospital admission and assessment, and both patients were started on either multiple daily injections of insulin (MDI, adult subject) or on continuous subcutaneous insulin infusion (subcutaneous insulin infusion 
(CSII), paediatric subject) as part of in-hospital care. However, follow-up glycaemic monitoring, insulin adjustment and education were substantially provided through telemedicine and using ambulatory glucose profiles and interpretive summary reports generated through CGM initiated while in hospital. In both cases, the subjects were successfully managed via telemedicine. In the UK, led by the national Diabetes Technology Network, a donation of sensors was used to support rapid discharge and remote follow-up of patients in this setting [53].

\section{FEAR OF INFECTION CHANGES ENGAGEMENT WITH HEALTH SERVICES FOR PEOPLE WITH DIABETES}

People with diabetes have significant COVID19-specific worries related to their diabetes. Social distancing gives rise to stressors that lead to anxiety and this may be exacerbated for people with diabetes who can be subject to advice for stricter isolation. A survey of 1396 people with diabetes in Denmark [54] found that the most prevalent diabetes-specific worry related to COVID-19 was fear of being overly affected by the virus (56\% respondents) along with being labelled as a high-risk group (39\% respondents) and an inability to manage their diabetes if infected (28\% respondents). In general, improvements in psychosocial health started to occur during the first reopening phase after the initial survey responses.

It is likely that this fear of infection contributes to a reluctance to visit medical centres during COVID. There is evidence that rates of admission for significant macrovascular disease are lower than usual, which may reflect reluctance of people to attend hospital. Although not specific to diabetes, data from Kaiser Permanente in the USA showed a $48 \%$ reduction in hospitalizations for acute myocardial infarction during the early weeks of lockdown [55]. Similarly, a study in France [56] has indicated that, although the overall incidence of stroke remained the same, fewer patients presented for neurology assessment within the therapeutic window as a consequence of anxieties over COVID transmission.

Fear of attending hospitals since March 2020 has had significant impacts for people with diabetes, with consequent outcomes for nonCOVID severe illness [57]. A survey of 4075 paediatricians in the UK and Ireland [58] indicated that symptomatic DKA was the most common problem that resulted from fear of attendance, separately from new-onset diabetes. Reports indicate that during the COVID-19 pandemic lockdown, the rate of DKA has increased amongst children with newly diagnosed T1D [59], including an increase in more severe cases [59-61]. This is accompanied by reports of more prevalent presentation of severe DKA in COVID-positive children with established T1D [61]. It is likely that the increase in severity in new or established cases coincides with delayed attendance at hospitals due to fear of COVID. Regular education of the whole society about the symptoms of diabetes could contribute to faster diagnosis of T1D and reduction of DKA prevalence, along with more rigorous adherence to 'sick-day rules' which are recommended for established T1D in such situations [62, 63].

Risk of DKA for people with T2D may be exacerbated by COVID infection. A series of cases have been described in which people with T2D and no history of DKA have presented at hospital with new-onset DKA, likely precipitated by COVID infection [64]. People with T1D are also at highest risk of DKA during COVIDrelated social lockdown, possibly related to potential changes in access to insulin or SMBG test strips [64]. Under these circumstances the value of telemonitoring with CGM can make the difference between early intervention and treatment, or a potentially life-threatening acute DKA episode. Both the FUTURE study in three specialist diabetes centres in Belgium [65] and the larger nationwide RELIEF study in France [66] have reported a significant fall in acute diabetes events (ADE), including DKA, after reimbursement of the FreeStyle Libre CGM system was approved within each health service. A recent retrospective, real-world analysis of a medical insurance claims database in the 
USA has shown a similar fall in ADE and related hospitalizations, including for DKA, once the FreeStyle Libre system was prescribed for people with diabetes [67]. Given the additional COVID-related risks for people with diabetes and prior hospitalization for DKA [8], the benefits of telemonitoring are strongly emphasised as they enable diabetes care at a distance and minimise metabolic deterioration and ADEs.

\section{RISK STRATIFICATION AND PRIORITIES FOR TELEMONITORING, TELEMEDICINE OR ATTENDANCE IN CLINIC}

The current reliance on telemedicine for managing people with diabetes will persist, not just in the near future but as part of standard care as diabetes services evolve to accommodate the successes and challenges of the COVID pandemic. However, it is important to acknowledge that telemedicine must be viewed in context. Although telemedicine during COVID has been largely welcomed as a positive experience in people with T1D, it is not universally appreciated. A survey of 7477 individuals across Europe, North America, South American, Africa and Asia has highlighted both the pros and cons [68]. Thirty per cent of respondents reported that their healthcare access had suffered during COVID and the majority (86\%) found remote consultations useful, with $75 \%$ indicating that they would continue with remote appointments in the future. This covered all age groups, including those over 65 years old. However, a group of respondents reported a negative perception of telemedicine. These were typically male and poorly controlled (HbA1c $>9.0 \%)$. The context of their reluctance to participate in telemedicine was unclear, whether it was down to lack of engagement with their own diabetes or lack of engagement with telemedicine.

What is clear is that telemedicine without telemonitoring in diabetes is a harder proposition. People with diabetes are at greater risk at every step of the natural history of COVID-19, from first infection through to severe disease, hospitalization and death $[6,35,36]$. Importantly, these risks reflect known attributes of people with diabetes, including type and duration of diabetes, longer-term control (HbA1c), short-term hyperglycaemia, comorbid and intercurrent disease, ethnicity and socio-economic status. Practical guidance for managing people with diabetes during COVID-19 has been published [62] and telemonitoring with CGM means that important parts of the risk profiles can be managed, both via telemedicine and through in-person consultation at a diabetes centre. The future of telemedicine is not simply about keeping people away from hospitals, it is equally about knowing who should be asked to come to the clinic and when. Thus, we see a future for diabetes care that prioritises people with diabetes for appropriate consultations based on their glucose metrics and other risk markers. Naturally, further adoption of telemedicine is part of clinical care for the many people whose diabetes can be managed with a clear view of their glucose metrics. It must also be pointed out that certain care processes will require in-clinic visits at a certain frequency, e.g. diabetes-related foot disease. Similarly, people with more acute disease will not easily fit the transition to telemedicine. These include those with significant hypoglycaemia unawareness or fear of hypoglycaemia, as well as people with frequent diabetesrelated admission for DKA or hyperosmolar hyperglycaemic state (HHS) [69]. This also applies to people with diabetes with comorbid disease and risks for cardiovascular or cerebrovascular events, who should be seen in-clinic at a frequency that reflects the urgency of their condition.

\section{DIABETES SERVICES ALREADY EMPLOY TOOLS NEEDED FOR TELEMEDICINE AND TELEMONITORING}

The virtual diabetes clinic has been a goal of healthcare systems and expert diabetes professionals for some time. Based around the growing number of technologies that enable diabetes care, telemedicine has been proposed as an 
important solution to the need to expand care for the benefit of people with diabetes, whilst improving efficiencies and rationalizing costs. As recently as February 2020, less than a month before the COVID pandemic was declared, an expert panel endorsed the opportunities and challenges of making telemedicine a standard of care for the management of diabetes [33]. In doing so they identified barriers for system interoperability within a diabetes health ecosystem and HCP reimbursement. In the UK, an expert panel recommended a risk stratification and risk-based follow-up approach using telemonitoring to help stratify people into red, amber or green categories [69].

The COVID-19 pandemic has shortcut some of these important conversations, disrupting the system and driving change in a manner that could not have been predicted. In doing so, the most agile services have emphasised and adopted systems and technologies that support people with diabetes in new models of care that minimise their need to attend busy medical centres. It is not a coincidence that the early adopters of new service designs are paediatric diabetes clinics $[9,23,70]$, one of which reports more than $80 \%$ of scheduled visits had been accomplished by telemedicine within 3 weeks of starting, with fewer missed appointments [70].

It can be argued that paediatric services are more agile in this regard because diabetes management enabling technology is more prevalent amongst younger children with diabetes [71]. The value of this is confirmed by recent outcomes from the SWEET project, a multinational network of more than 100 paediatric diabetes centres with a mission to establish standards of care in paediatric diabetes worldwide [72]. Data on 25,654 children and adolescents from SWEET [73] showed that children and adolescents using continuous CSII pumps, CGM systems or both had significantly lower HbA1c compared to those using insulin injections and SMBG. The proportion of DKA episodes was lower in the group using an insulin pump alone or in tandem with a CGM sensor. Of note, reported episodes of severe hypoglycaemia were lower in the group using an insulin pump without a CGM sensor, but increased in the group using CGM alone, compared to those using insulin injections and SMBG. This would suggest that the full impact of each of these enabling technologies, though demonstrated, can be further improved.

Together, these real-world insights indicate that the need for technology interoperability is already being met for effective telemedicine in diabetes, with new ways of working that leverage existing digital health ecosystems. It is clear that this can improve in the future, with systematic application of additional tools that can enhance the emerging practice of telemedicine, but it is effective now. A further barrier to telemedicine is also being dismantled as a consequence of COVID, that of reimbursement. Healthcare payers are widening existing provisions for telemedicine or creating them where they did not exist [74-76].

\section{CONCLUSIONS}

Telemedicine and telemonitoring have been transformed from an aspirational goal to become the de facto standard of care for diabetes management during the COVID-19 public health emergency in the developed world. This has been in response to the need to protect people with diabetes who are at immediate and greater risk of severe disease, hospitalization and death from COVID-19. However, we must acknowledge that COVID is also an instructive use case that highlights the vulnerability of people with diabetes in situations that disrupt the process of standard care. Ultimately, as well as managing people with diabetes at a distance, the value of routine telemonitoring must also be to identify groups of at-risk individuals who need in-person consultation and care.

Telemonitoring of glucose data has been an invaluable tool in maintaining glycaemic control for a significant subset of those able to access this technology, most evidently for people with $\mathrm{T} 1 \mathrm{D}$, including paediatric and adult groups. The case for wider application of glucose telemonitoring is clear but still faces significant hurdles. Central to these is acknowledgement of the value of telemonitoring and reimbursement for this along with 
increased access to CGM systems. The cost-benefit calculation has been strongly weighted towards the benefits during COVID but further action is needed to conclusively demonstrate the long-term financial savings. Education in regard of telemonitoring and telemedicine is also critical to the successful implementation of technologies that better enable diabetes care, both for HCPs and for people with diabetes. Just as important are the imperatives to manage data for enhanced diabetes care. The COVID public health emergency has shown what can be achieved when the current technology is put under the spotlight, but this can be better supported with systematic changes to diabetes care. Integration of data uplink and data sharing systems is a recognised unmet need in this context. Additionally, with better systems integration comes the requirement for an information technology (IT) specialist contribution, not as a support service but as an established member of the diabetes multidisciplinary team. Action on these aspects of diabetes digital health is a clear imperative.

Telemedicine is an acknowledged part of the post-COVID world but telemonitoring via CGM is still possible only for a subset of people with diabetes. The diabetes services adapting most quickly to the needs of care of people with diabetes appear to be those with the most experience and confidence of working with diabetes health technologies and creating their own diabetes health ecosystems. These are often paediatric services.

\section{ACKNOWLEDGEMENTS}

Funding. Sponsorship for this study and journal's Rapid Service Fee were funded by Abbott Diabetes Care.

Medical Writing Assistance. Editorial assistance in the preparation of this manuscript was provided by Dr Robert Brines of Bite Medical Consulting.

Authorship. All named authors meet the International Committee of Medical Journal
Editors (ICMJE) criteria for authorship for this article, take responsibility for the integrity of the work as a whole, and have given their approval for this version to be published.

Author Contributions. Thomas Danne and Alexander Seibold had the idea for the article, all authors contributed to the literature search and data analysis. Thomas Danne, Catarina Limbert and Alexander Seibold drafted the first version of the manuscript, all authors contributed to subsequent versions and read and approved the final manuscript. Editorial assistance in the preparation of this article was provided by Rob Brines and Wiebke Jessen. Support for this assistance was funded by Abbott Diabetes Care.

Disclosures. Thomas Danne reports grants and personal fees from Abbott, AstraZeneca, Boehringer, DexCom, Lilly, Medtronic, Novo Nordisk, Roche, Sanofi outside the submitted work and is a shareholder of DreaMed Ltd. Catarina Limbert reports grants and personal fees from Abbott, Ipsen and Sanofi. Pratik Choudhary reports grants and personal fees from Abbott, Dexcom, Lilly, Novo Nordisk, Sanofi and Insulet. Manuel Puig-Domingo reports grants, consultant and speaker fees from Sanofi, Novo Nordisk, AstraZeneca, Lilly, Recordati, Pfizer, Ipsen and Novartis outside the submitted work. Eric Renard reports personal fees as consultant/advisor for Abbott, Air Liquide, AstraZeneca, Boehringer Ingelheim, Cellnovo, Dexcom, Eli Lilly, Insulet, Johnson \& Johnson (Animas, LifeScan), Medirio, Medtronic, Novo Nordisk, Roche Diagnostics, Sanofi-Aventis and Tandem, and research grant/material support from Abbott, Dexcom, Insulet, Roche Diagnostics and Tandem. Stefano Del Prato has served on the scientific board and received honoraria for consulting fees from AstraZeneca, Boehringer Ingelheim, Eli Lilly, GlaxoSmithKline, Merck \& Co., Novartis Pharmaceuticals, Novo Nordisk, sanofi, servier, Takeda Pharmaceuticals.

Compliance with Ethics Guidelines. This article is based on previously conducted studies and does not contain any new studies with 
human participants or animals performed by any of the authors.

Data Availability. Data sharing is not applicable to this article as no new data sets were generated during the current study.

Open Access. This article is licensed under a Creative Commons Attribution-NonCommercial 4.0 International License, which permits any non-commercial use, sharing, adaptation, distribution and reproduction in any medium or format, as long as you give appropriate credit to the original author(s) and the source, provide a link to the Creative Commons licence, and indicate if changes were made. The images or other third party material in this article are included in the article's Creative Commons licence, unless indicated otherwise in a credit line to the material. If material is not included in the article's Creative Commons licence and your intended use is not permitted by statutory regulation or exceeds the permitted use, you will need to obtain permission directly from the copyright holder. To view a copy of this licence, visit http://creativecommons.org/licenses/bync/4.0/.

\section{REFERENCES}

1. Zhou F, Yu T, Du R, et al. Clinical course and risk factors for mortality of adult inpatients with COVID-19 in Wuhan, China: a retrospective cohort study. Lancet. 2020;395:1054-62.

2. Bode B, Garrett V, Messler J, et al. Glycemic characteristics and clinical outcomes of COVID-19 patients hospitalized in the United States. J Diabetes Sci Technol. 2020;14:813-21.

3. Chen Y, Yang D, Cheng B, et al. Clinical characteristics and outcomes of patients with diabetes and COVID-19 in association with glucose-lowering medication. Diabetes Care. 2020;43:1399-407.

4. Holman N, Knighton P, Kar P, et al. Risk factors for COVID-19-related mortality in people with type 1 and type 2 diabetes in England: a population-based cohort study. Lancet Diabetes Endocrinol. 2020;8: 823-33.
5. Istituto Superiore di Sanità. Report of characteristics of patients who died positive for COVID-19 in Italy. 2020 (in Italian). https://www.epicentro.iss.it/ coronavirus/bollettino/Report-COVID-2019_17_ marzo-v2.pdf. Accessed 18 June 2021.

6. Mantovani A, Byrne $\mathrm{CD}$, Zheng $\mathrm{M}-\mathrm{H}$, Targher G. Diabetes as a risk factor for greater COVID-19 severity and in-hospital death: a meta-analysis of observational studies. Nutrition Metab Cardiovasc Dis. 2020;30:1236-48.

7. Barron E, Bakhai C, Kar P, et al. Associations of type 1 and type 2 diabetes with COVID-19-related mortality in England: a whole-population study. Lancet Diabetes Endocrinol. 2020;8:813-22.

8. McGurnaghan SJ, Weir A, Bishop J, et al. Risks of and risk factors for COVID-19 disease in people with diabetes: a cohort study of the total population of Scotland. Lancet Diabetes Endocrinol. 2021;9:82-93.

9. Danne T, Limbert C. COVID-19 pandemic, type 1 diabetes and technology: why paediatric patients are leading the way. Lancet Diabetes Endocrinol. 2020;8:465-7. https://doi.org/10.1016/S2213$8587[20] 30155-8$.

10. Cardona-Hernandez R, Cherubini V, Iafusco D, Schiaffini R, Luo X, Maahs DM. Children and youth with diabetes are not at increased risk for hospitalization due to COVID-19. Pediatr Diabetes. 2021;22:202-6.

11. Wake DJ, Gibb FW, Kar P, et al. Endocrinology in the time of COVID-19: remodelling diabetes services and emerging innovation. Eur J Endocrinol. 2020;183:G67-77.

12. Danne $\mathrm{T}$, Nimri R, Battelino $\mathrm{T}$, et al. International consensus on use of continuous glucose monitoring. Diabetes Care. 2017;40(12):1631-40.

13. Battelino T, Danne T, Bergenstal RM, et al. Clinical targets for continuous glucose monitoring data interpretation: recommendations from the international consensus on time in range. Diabetes Care. 2019;42(8):1593-603.

14. Barchetta I, Cimini FA, Bertoccini L, et al. Effects of work status changes and perceived stress on glycaemic control in individuals with type 1 diabetes during COVID-19 lockdown in Italy. Diabetes Res Clin Pract. 2020;170:108513.

15. Mesa A, Viñals C, Pueyo I, et al. The impact of strict COVID-19 lockdown in Spain on glycemic profiles in patients with type 1 diabetes prone to hypoglycemia using standalone continuous glucose monitoring. Diabetes Res Clin Pract. 2020;167: 108354. 
16. Viñals C, Mesa A, Roca D, et al. Management of glucose profile throughout strict COVID-19 lockdown by patients with type 1 diabetes prone to hypoglycaemia using sensor-augmented pump. Acta Diabetol. 2021;58(3):383-8. https://doi.org/ 10.1007/s00592-020-01625-2.

17. Bonora BM, Boscari F, Avogaro A, Bruttomesso D, Fadini GP. Glycaemic control among people with type 1 diabetes during lockdown for the SARS-CoV2 outbreak in Italy. Diabetes Ther. 2020;11: 1369-79.

18. Prabhu Navis J, Leelarathna L, Mubita W, et al. Impact of COVID-19 lockdown on flash and realtime glucose sensor users with type 1 diabetes in England. Acta Diabetol. 2020;58(2):231-7.

19 Capaldo B, Annuzzi G, Creanza A, et al. Blood glucose control during lockdown for COVID-19: CGM metrics in Italian adults with type 1 diabetes. Diabetes Care. 2020;43:e88-9. https://doi.org/10.2337/ dc20-1127.

20. Potier L, Hansel B, Larger E, et al. Stay-at-home orders during the COVID-19 pandemic, an opportunity to improve glucose control through behavioral changes in type 1 diabetes. Diabetes Care. 2020;44:839-43.

21. Schiaffini R, Barbetti F, Rapini N, et al. School and pre-school children with type 1 diabetes during Covid-19 quarantine: the synergic effect of parental care and technology. Diabetes Res Clin Pract. 2020;166:108302.

22. Dover AR, Ritchie SA, McKnight JA, et al. Assessment of the effect of the COVID-19 lockdown on glycaemic control in people with type 1 diabetes using flash glucose monitoring. Diabetic Med. 2021;38(1):e14374.

23. Braune K, Boss K, Schmidt-Herzel J, et al. Shaping workflows in digital and remote diabetes care during the COVID-19 pandemic via a service design: prospective, longitudinal, open-label feasibility trial. JMIR Mhealth Uhealth. 2021;9(4):e24374.

24. Boscari F, Ferretto S, Uliana A, Avogaro A, Bruttomesso D. Efficacy of telemedicine for persons with type 1 diabetes during Covid19 lockdown. Nutr Diabetes. 2021;11:1.

25. Rachmiel M, Lebenthal Y, Mazor-Aronovitch K, et al. Glycaemic control in the paediatric and young adult population with type 1 diabetes following a single telehealth visit-what have we learned from the COVID-19 lockdown? Acta Diabetol. 2021;58(6):697-705.

26. Alharthi SK, Alyusuf EY, Alguwaihes AM, Alfadda A, Al-Sofiani ME. The impact of a prolonged lockdown and use of telemedicine on glycemic control in people with type 1 diabetes during the COVID-19 outbreak in Saudi Arabia. Diabetes Res Clin Pract. 2021;173:108682.

27. Park S-D, Kim S-W, Moon JS, et al. Impact of social distancing due to coronavirus disease 2019 on the changes in glycosylated hemoglobin level in people with type 2 diabetes mellitus. Korean Diabetes J. 2020;45:109-14.

28. Karatas S, Yesim T, Beysel S. Impact of lockdown COVID-19 on metabolic control in type 2 diabetes mellitus and healthy people. Prim Care Diabetes. 2021;15:424-7.

29. Falcetta P, Aragona M, Ciccarone A, et al. Impact of COVID-19 lockdown on glucose control of elderly people with type 2 diabetes in Italy. Diabetes Res Clin Pract. 2021;174: 108750. https://doi.org/10. 1016/j.diabres.2021.108750.

30. Rastogi A, Hiteshi P, Bhansali A. Improved glycemic control amongst people with long-standing diabetes during COVID-19 lockdown: a prospective, observational, nested cohort study. Int J Diabetes Dev Ctries. 2020;40:476-81.

31. Ruissen MM, Regeer H, Landstra CP, et al. Increased stress, weight gain and less exercise in relation to glycemic control in people with type 1 and type 2 diabetes during the COVID-19 pandemic. BMJ Open Diabetes Res Care. 2021;9:e002035.

32. Verma A, Rajput R, Verma S, Balania VKB, Jangra B. Impact of lockdown in COVID 19 on glycemic control in patients with type 1 diabetes mellitus. Diabetes Metab Syndrome Clin Res Rev. 2020;14: 1213-6.

33. Phillip M, Bergenstal RM, Close KL, et al. The digital/virtual diabetes clinic: the future is now-recommendations from an international panel on diabetes digital technologies introduction. Diabetes Technol Ther. 2021;23:146-54.

34. Bain SC, Czernichow S, Bøgelund M, et al. Costs of COVID-19 pandemic associated with diabetes in Europe: a health care cost model. Curr Med Res Opin. 2020;37:1-16.

35. Stokes EK, Zambrano LD, Anderson KN, et al. Coronavirus disease 2019 case surveillance-United States, January 22-May 30, 2020. Morbidity Mortal Wkly Rep. 2020;69:759-65.

36. Merzon E, Green I, Shpigelman M, et al. Haemoglobin A1c is a predictor of COVID-19 severity in patients with diabetes. Diabetes Metabolism Res Rev. 2021;37(5):e3398. 
37. Williamson EJ, Walker AJ, Bhaskaran K, et al. Factors associated with COVID-19-related death using OpenSAFELY. Nature. 2020;584:430-6.

38. Carrasco-Sánchez FJ, López-Carmona MD, Martínez-Marcos FJ, et al. Admission hyperglycaemia as a predictor of mortality in patients hospitalized with COVID-19 regardless of diabetes status: data from the Spanish SEMI-COVID-19 Registry. Ann Med. 2020;53:103-16.

39. Lampasona V, Secchi M, Scavini M, et al. Antibody response to multiple antigens of SARS-CoV-2 in patients with diabetes: an observational cohort study. Diabetologia. 2020;63:2548-58.

40. Coppelli A, Giannarelli R, Aragona $\mathrm{M}$, et al. Hyperglycemia at hospital admission is associated with severity of the prognosis in patients hospitalized for COVID-19: the Pisa COVID-19 Study. Diabetes Care. 2020;43:2345-8.

41. Müller JA, Groß R, Conzelmann C, et al. SARS-CoV2 infects and replicates in cells of the human endocrine and exocrine pancreas. Nat Metab. 2021;3(2):149-65.

42 Atkinson MA, Powers AC. Distinguishing the real from the hyperglycemia: does COVID-19 induce diabetes? Lancet Diab Endocrinol. 2021. https://doi. org/10.1016/S2213-8587(21)00087-5.

43. Brufsky A. Hyperglycemia, hydroxychloroquine, and the COVID-19 pandemic. J Med Virol. 2020;92: 770-5.

44. Shen Y, Fan X, Zhang L, et al. Thresholds of glycemia and the outcomes of COVID-19 complicated with diabetes: a retrospective exploratory study using continuous glucose monitoring. Diabetes Care. 2021;44(4):976-82. https://doi.org/10.2337/ dc20-1448.

45. Klonoff DC, Messler JC, Umpierrez GE, et al. Association between achieving inpatient glycemic control and clinical outcomes in hospitalized patients with COVID-19: a multicenter, retrospective hospital-based analysis. Diabetes Care. 2020;44: 578-85.

46. Papadopoulos VP, Koutroulos M-V, Zikoudi D-G, et al. Diabetes-related acute metabolic emergencies in COVID-19 patients: a systematic review and meta-analysis. Diabetol Int. 2021;23:1-15. https:// doi.org/10.1007/s13340-021-00502-9.

47. Yang J-K, Lin S-S, Ji X-J, Guo L-M. Binding of SARS coronavirus to its receptor damages islets and causes acute diabetes. Acta Diabetol. 2010;47:193-9.

48. Hollstein T, Schulte DM, Schulz J, et al. Autoantibody-negative insulin-dependent diabetes mellitus after SARS-CoV-2 infection: a case report. Nat Metabolism. 2020;2:1021-4.

49 Unsworth R, Wallace S, Oliver NS, et al. New-onset type 1 diabetes in children during COVID-19: multicenter regional findings in the U.K. Diabetes Care. 2020;43(11):e170-1.

50. Li H, Tian S, Chen T, et al. Newly diagnosed diabetes is associated with a higher risk of mortality than known diabetes in hospitalized patients with COVID-19. Diabetes Obes Metab. 2020;22: 1897-906.

51. Fadini GP, Morieri ML, Boscari F, et al. Newly-diagnosed diabetes and admission hyperglycemia predict COVID-19 severity by aggravating respiratory deterioration. Diabetes Res Clin Pract. 2020;168:108374.

52. Garg SK, Rodbard D, Hirsch IB, Forlenza GP. Managing new-onset type 1 diabetes during the COVID-19 pandemic: challenges and opportunities. Diabetes Technol Ther. 2020;22:431-9.

53. Association of British Clinical Diabetologists. Donation of Freestyle Libre Sensors. 2020. https:// abcd.care/announcement/donation-freestyle-libresensors. Accessed 14 July 2021.

54. Joensen LE, Madsen KP, Holm L, et al. Diabetes and COVID-19: psychosocial consequences of the COVID-19 pandemic in people with diabetes in Denmark-what characterizes people with high levels of COVID-19-related worries? Diabetic Med. 2020;37:1146-54.

55. Solomon MD, McNulty EJ, Rana JS, et al. The Covid19 pandemic and the incidence of acute myocardial infarction. N Engl J Med. 2020;383:691-3.

56. Pop R, Quenardelle V, Hasiu A, et al. Impact of the COVID-19 outbreak on acute stroke pathways-insights from the Alsace region in France. Eur J Neurol. 2020;27:1783-7.

57. Lazzerini M, Barbi E, Apicella A, Marchetti F, Cardinale F, Trobia G. Delayed access or provision of care in Italy resulting from fear of COVID-19. Lancet Child Adolesc Health. 2020;4:e10-1.

58. Lynn RM, Avis JL, Lenton S, Amin-Chowdhury Z, Ladhani SN. Delayed access to care and late presentations in children during the COVID-19 pandemic: a snapshot survey of 4075 paediatricians in the UK and Ireland. Arch Dis Child. 2021;106: e8-e8.

59. Dżygało K, Nowaczyk J, Szwilling A, Kowalska A. Increased frequency of severe diabetic ketoacidosis at type 1 diabetes onset among children during COVID-19 pandemic lockdown: an observational 
cohort study. Pediatric Endocrinol Diabetes Metab. 2020;26:167-75.

60. Lawrence C, Seckold R, Smart C, et al. Increased paediatric presentations of severe diabetic ketoacidosis in an Australian tertiary centre during the COVID-19 pandemic. Diabetic Med. 2021;38: e14417.

61. Ho J, Rosolowsky E, Pacaud D, et al. Diabetic ketoacidosis at type 1 diabetes diagnosis in children during the COVID-19 pandemic. Pediatr Diabetes. 2021;22:552-7.

62. Bornstein SR, Rubino F, Khunti K, et al. Practical recommendations for the management of diabetes in patients with COVID-19. Lancet Diabetes Endocrinol. 2020;8:546-50.

63. Laffel LM, Limbert C, Phelan H, Virmani A, Wood J, Hofer SE. ISPAD Clinical Practice Consensus Guidelines 2018: sick day management in children and adolescents with diabetes. Pediatr Diabetes. 2018;19:193-204.

64. Croft A, Bucca A, Jansen JH, et al. First-time diabetic ketoacidosis in type 2 diabetics with Covid-19 infection: a novel case series. J Emerg Med. 2020;59: e193-197.

65. Charleer S, Block CD, Huffel LV, et al. Quality of life and glucose control after 1 year of nationwide reimbursement of intermittently scanned continuous glucose monitoring in adults living with type 1 diabetes (FUTURE): a prospective observational real-world cohort study. Diabetes Care. 2020;43: 389-97.

66. Roussel R, Riveline J-P, Vicaut E, et al. Important drop in rate of acute diabetes complications in people with type 1 or type 2 diabetes after initiation of flash glucose monitoring in France: The RELIEF Study. Diabetes Care. 2021. https://doi.org/10. 2337/dc20-1690.

67. Bergenstal RM, Kerr MSD, Roberts GJ, Souto D, Nabutovsky Y, Hirsch IB. Flash CGM is associated with reduced diabetes events and hospitalizations in insulin-treated type 2 diabetes. J Endocr Soc. 2021;5:bvab013.

68. Scott SN, Fontana FY, Züger T, Laimer M, Stettler C. Use and perception of telemedicine in people with type 1 diabetes during the COVID-19 pandemicresults of a global survey. Endocrinol Diabetes Metabolism. 2021;4:e00180.

69. Choudhary P, Wilmot EG, Owen K, Patel DC, Mills $\mathrm{L}$, et al. A roadmap to recovery: ABCD recommendations on risk stratification of adult patients with diabetes in the post-COVID-19 era. Diabet Med.
2021;38(3): e14462. https://doi.org/10.1111/dme. 14462 .

70. March CA, Flint A, DeArment D, Gilliland A, Kelly $\mathrm{K}$, Rizzitano E, et al. Paediatric diabetes care during the COVID-19 pandemic: lessons learned in scaling up telemedicine services. Endocrinol Diabetes Metab. 2021;4:e00202.

71. DeSalvo DJ, Miller KM, Hermann JM, Maahs DM, Hofer SE, Clements MA, et al. Continuous glucose monitoring and glycemic control among youth with type 1 diabetes: International comparison from the T1D Exchange and DPV Initiative. Pediatr Diabetes. 2018;19:1271-5.

72. Gerhardsson P, Schwandt A, Witsch M, Kordonouri O, Svensson J, Forsander G, Battelino T, Veeze H, Danne T. The SWEET project 10-year benchmarking in 19 countries worldwide is associated with improved HbA1c and increased use of diabetes technology in youth with type 1 diabetes. Diabetes Technol Ther. 2021. https://doi.org/10.1089/dia. 2020.0618 .

73. Cardona-Hernandez R, Schwandt A, Alkandari H, et al. Glycemic outcome associated with insulin pump and glucose sensor use in children and adolescents with type 1 diabetes. Data from the international pediatric registry SWEET. Diabetes Care. 2021;44(5):1176-84.

74. Ohannessian R, Duong TA, Odone A. Global Telemedicine Implementation and Integration Within Health Systems to Fight the COVID-19 Pandemic: A Call to Action. JMIR Public Heal Surveillance. 2020;6:e18810.

75. Demeke HB, Merali S, Marks S, Pao LZ, Romero L, Sandhu $\mathrm{P}$, et al. Trends in use of telehealth among health centers during the COVID-19 PandemicUnited States, June 26-November 6, 2020. Morbidity Mortal Wkly Rep. 2021;70:240-4.

76. Centers for Medicare \& Medicaid Services. Telemedicine health care provider fact sheet. Baltimore, MD: US Department of Health and Human Services, Centers for Medicare \& Medicaid Services; 2020. . 2020. https://www.cms.gov/newsroom/fact-sheets/ medicare-telemedicine-health-care-provider-factsheet. Accessed 14 July 2021.

77. Christoforidis A, Kavoura E, Nemtsa A, Pappa K, Dimitriadou M. Coronavirus lockdown effect on type 1 diabetes management on children wearing insulin pump equipped with continuous glucose monitoring system. Diabetes Res Clin Pract. 2020;166:108307.

78. Fernández E, Cortazar A, Bellido V. Impact of covid19 lockdown on glycemic control in patients with 
type 1 diabetes. Diabetes Res Clin Pract. 2020;166: 108348.

79. Cotovad-Bellas L, Tejera-Pérez C, Prieto-Tenreiro A, Sánchez-Bao A, Bellido-Guerrero D. The challenge of diabetes home control in COVID-19 times: proof is in the pudding. Diabetes Res Clin Pract. 2020;168:108379.

80. Caruso I, Molfetta SD, Guarini F, et al. Reduction of hypoglycaemia, lifestyle modifications and psychological distress during lockdown following SARS-CoV-2 outbreak in type 1 diabetes. Diabetes Metab Res Rev. 2020. https://doi.org/10.1002/dmrr. 3404 .

81. Aragona M, Rodia C, Bertolotto A, et al. Type 1 diabetes and COVID-19: the "Lockdown effect." Diabetes Res Clin Pract. 2020;108468. https://doi. org/10.1016/j.diabres.2020.108468.

82. Di Dalmazi G, Maltoni G, Bongiorno C, et al. Comparison of the effects of lockdown due to COVID-19 on glucose patterns among children, adolescents, and adults with type 1 diabetes: CGM study. BMJ Open Diabetes Res Care. 2020;8: e001664.

83. Brener A, Mazor-Aronovitch K, Rachmiel M, et al. Lessons learned from the continuous glucose monitoring metrics in pediatric patients with type 1 diabetes under COVID-19 lockdown. Acta Diabetol. 2020;57:1511-7.

84 Pla B, Arranz A, Knott C, et al. Impact of COVID-19 lockdown on glycemic control in adults with type 1 diabetes mellitus. J Endocr Soc. 2020;4:bvaa149.

85. Predieri B, Leo F, Candia F, et al. Glycemic control improvement in Italian children and adolescents with type 1 diabetes followed through telemedicine during lockdown due to the COVID-19 pandemic. Front Endocrinol. 2020;11:595735.

86. Sanchez-Conejero MS, Amigo JG de B, Bravo MLT, Jiménez JM de N. Repercusión del confinamiento por COVID-19 sobre el control glucémico en niños y adolescentes con diabetes mellitus tipo 1. An Pediatr (Engl Ed). 2021. https://doi.org/10.1016/j. anpedi.2020.12.021.

87. Marigliano M, Maffeis C. Glycemic control of children and adolescents with type 1 diabetes improved after COVID-19 lockdown in Italy. Acta Diabetol. 2021;58(5):661-4.

88. van der Linden J, Welsh JB, Hirsch IB, Garg SK. Realtime continuous glucose monitoring during the coronavirus disease 2019 pandemic and its impact on time in range. Diabetes Technol Ther. 2021;23:S$1-\mathrm{S}-7$. 